
conditions of the Creative Commons Attribution-NonCommercial-ShareAlike licence $<\mathrm{http}: / /$ creativecommons.org/licenses/by-nc-sa/2.5/>. The written permission of Cambridge University Press must be obtained for commercial re-use.

doi:10.1017/So144686X12000062

\title{
Why are the oldest old less generous? Explanations for the unexpected age-related drop in charitable giving
}

\author{
PAMALA WIEPKING* and RUSSELL N. JAMES III†
}

\begin{abstract}
Previous research has demonstrated that the generally positive relationship between age and the presence of charitable giving becomes negative at the oldest ages. We investigate potential causes of this drop in charitable giving among the oldest old including changes in health, cognition, egocentric networks, religious attendance, and substitution of charitable bequest planning. A longitudinal analysis of data from the United States Health and Retirement Survey indicates that the drop in charitable giving is mediated largely by changes in the frequency of church attendance, with only modest influences from changes in health and cognition.
\end{abstract}

KEY WORDS - philanthropy, charitable giving, cognition, health, oldest old.

\section{Introduction}

Non-profit sectors in Western societies rely strongly on the voluntary contributions of those of older age. The majority of all deductible charitable gifts are made by those over age 55 , with most coming from those over 65 (Bekkers and Wiepking 2011; Internal Revenue Service 2007). Those of older age are generally known to display higher levels and more different forms of prosocial behaviour (Bekkers and Wiepking 2007; Choi and Kim 2010). Prosocial behaviour represents a 'broad category of acts that are ... beneficial to other people' (Penner et al. 2005: 366). Examples of prosocial behaviour are formal helping behaviour (charitable giving, volunteering,

* Department of Sociology \& Erasmus Centre for Strategic Philanthropy, Faculty of Social Sciences, Erasmus University Rotterdam, The Netherlands.

$\dagger$ Department of Personal Financial Planning, Texas Tech University, Lubbock, Texas, USA. 
donating blood and organs) and informal helping behaviour (helping family, friends or strangers). The positive relationship between age and prosocial behaviour can largely be accounted for by lifecycle effects, such as higher levels of income and more leisure time that become available with older age (Barlow and Hainsworth 2001; Schervish, Havens and O'Herlihy 2006). Having more financial resources and time available has a positive influence on the amount of time and money spent helping others and supporting non-profit organisations (Bekkers and Wiepking 2007). In addition, some studies also find evidence for a cohort effect: more recent cohorts are increasingly active at an older age (Broese Van Groenou and Deeg 2010; Einolf 2009; Knulst and Eijck 2006). Broese Van Groenou and Deeg (2010) show that the social participation rates of 6o-69-year-olds in the Netherlands in 2002 were significantly higher than those of their agepeers in 1992. The increased social participation in the 2002 cohort can be explained by their higher average level of educational attainment and by their increased retirement age compared with the 1992 cohort. Using longitudinal data, Einolf (2009) predicts that in the United States of America (USA) the generation of baby-boomers (born 1946-1955) will be more active volunteers in the near future than the generations born $1936-1945$ or born $1926-1935$ were at the same ages.

With the large generation of baby-boomers arriving at or approaching retirement, this gives great promise for the future of the non-profit sector in Western societies (Havens and Schervish 2003). However, it remains to be seen whether this demographic trend is actually as positive for the financial support of the non-profit sector as it seems at first glance. Although age has generally been positively associated with charitable giving, when the overall positive linear trend is examined more closely, studies commonly find that the positive relationship between age and charitable giving becomes negative at the oldest ages. Several studies have found that charitable giving to non-profit organisations increases with age until age 75 and then declines with further age (Andreoni 2001; Hodgkinson and Weitzman 1996; Midlarsky and Hannah 1989). Other studies have found those over age 65 were less likely to be donors, such as in analyses of a national survey in Taiwan (Wu, Huang and Kao 2004), in analyses of charitable giving tax data in the USA (Daneshvary and Luksetich 1997), in a survey study of door-to-door giving in the Netherlands (Wiepking 2010), and in a door-to-door fundraising experiment involving 5 , OOO US households (Landry et al. 2006). Other studies have also suggested that amounts donated to charity increase until age 65 then decrease (Danko and Stanley 1986; Edmundson 1986; Halfpenny 1991).

Previous research has not yet led to an understanding of the lower incidence of giving at the oldest ages. In this article we examine why 
those of older age are less likely to be charitable donors than their younger counterparts. We formulate hypotheses about how decreasing health conditions and declining cognitive abilities in older age can account for the age-related drop in charitable giving. We will test our hypotheses with longitudinal analyses of five waves of the US Health and Retirement study (1998-2006), including 85,607 individuals over $5^{\text {o years }}$ of age.

In the gerontology literature, research generally tends to focus on individual outcomes of prosocial behaviour. A substantial stream of research is built around activity theory. This suggests prosocial behaviour may be beneficial due to increased participation in social activities, including formal and informal volunteering and giving, resulting in increased wellbeing and successful ageing of older adults (Choi and Kim 2010; Lemon, Bengtson and Peterson 1972; Longino and Karl 1982; Wheeler, Gorey and Greenblatt 1998). In this article we take a different approach, and examine how and why the oldest old experience a decline in charitable giving. Rather than a focus on individual outcomes we thus focus on societal outcomes. Understanding why older adults decrease their donations to nonprofit organisations will help these organisations to understand better the needs of their older donors, who form a substantial part of their donor base and on which they rely heavily for support and continuation of their operations. This increased understanding can possibly help decrease the age-related drop in charitable giving, for example by readjusting the communication between non-profit organisations and their donors of older age.

\section{Explanations for a decrease in giving at the oldest age}

Theoretically, we argue for two explanations of the declining likelihood of charitable giving in older age: declining physical health and decreasing cognitive abilities. We will formulate two complementary hypotheses to test these explanations: the health hypothesis and the cognitive ability hypothesis.

\section{The health hypothesis}

At the oldest age, people typically experience declining health conditions. For example in the USA, 18.7 per cent of the people between $6_{5}$ and 74 have ever been diagnosed with cancer. This statistic increases rapidly with age as 25.5 per cent of the people between 75 and 84 have ever been diagnosed with cancer, and 27.1 per cent of the people older than 84 have ever been 
diagnosed with cancer. The difference in health status at older age is even more pronounced for heart diseases. No less than 41.2 per cent of the people over 85 have been diagnosed with a heart disease, compared with 35.9 per cent for those between 75 and 84 years of age, and 26.7 per cent for those between $6_{5}$ and 75 years old. The chances of having a stroke double over $6_{5}$ years of age: while 6.7 per cent of the people between $6_{5}$ and 74 have experienced a stroke, this figure is 14 per cent for those over 84 years of age (NHIS 2006-o8).

Declining health conditions can result in a lower inclination to make charitable donations for several reasons. First, declining health generally leads to increasing medical costs. Greater health-care expenditure limits the amount of money available to spend on other things, and non-necessities benefiting others, such as charitable giving, may be among the first expenses cut (Nieswiadomy and Rubin 1995).

Secondly, many charitable donations are made in public, outside the donors' home environment. Consider for example religious donations, which compose the majority of charitable gifts in the USA (Giving USA 2009). Often these donations are made during a religious service. People with bad health are less likely to attend religious services, and hence less likely to experience these opportunities for donations to religious institutions. The same is true for some other types of donations. People with bad health may be less likely to make donations in street collections, and donations solicited through people's own social network due to a lower number of contacts.

Declining health in oldest age may coincide with a decreasing egocentric social network (Cornwell, Laumann and Schumm 2008; Hatch and Bulcroft 1992). Analysing a longitudinal sample of Dutch adults aged 6o-85, Van Tilburg and Broese van Groenou (2002) find that over a period of seven years average egocentric network size is stable. But they also find that social network size of older people is dynamic. About onethird of the mainly young old-respondents experienced an increase in social network size, while one-third of the mainly oldest respondents experienced a decrease in egocentric social network size. Larger egocentric social networks are replaced by more kin-centred networks, which facilitate higher levels of emotional support (Marsden 1987; Schnittker 2007). Declining health conditions in older age do lead to intensified contacts with existing network members, or to forming new contacts with more supportive network members, as predicted by socio-emotional selectivity theory (Shaw et al. 2007). Social contacts are an important driver for charitable donations (Wiepking and Maas 2009). Up to 85 per cent of charitable gifts are made following a request for a donation (Bryant et al. 2003). Decreasing egocentric social networks among older people with 
declining health limit the direct personal requests for charitable donations. This is important because personal requests for donations are much more successful than requests that do not involve personal contact between solicitor and donor (Bekkers 2005a). Hence, decreasing egocentric social networks can account for decreasing charitable donations by those of older age.

Fourthly, declining health conditions can lead to a decrease in charitable giving because people specify alternative ways of making donations. People who experience health issues at older age are more likely to draw up their will (Edwards 1991; Munnell and Sundén 2003). Death is a more salient issue in their lives (Baltes and Baltes 1990; Ma 2002; Maxfield et al. 2007). Rather than making inter vivos gifts, they may choose to include a charitable bequest to one or more charitable organisations in their will. A benefit of leaving a charitable bequest, compared with inter vivos giving, is that a charitable bequest can help people 'to live' on, an important motivation for charitable bequestors (Sargeant and Shang 2008). People are concerned with how they will be remembered after they are dead, and they can use charitable bequests to be remembered as altruistic and generous people. In a longitudinal

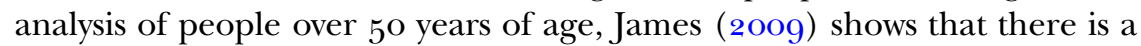
positive effect of being diagnosed with cancer on including a charitable bequest in one's will, while he finds no effect of changes in other health conditions.

Not only does declining health lead to alternative specifications of charitable gifts, such as charitable bequests, some people quit making donations to those unrelated to them at all when becoming seriously ill at older age. It is imaginable that declining health conditions lead older people to be more aware about the financial situation of their close family. Only after people perceive their family's financial needs will be taken care of after their passing will they be inclined to make charitable donations (Hurd 2009; Wiepking and Breeze 2012). Hence, the presence of alternative non-charitable beneficiaries and the perceived future level of financial security of these alternative beneficiaries is a serious inhibitor for making charitable donations by those of older age with declining health conditions.

We summarise the arguments for the lower inclination to make charitable donations resulting from declining health conditions in the health hypothesis:

$\mathrm{H}_{1}$ : Declining health conditions lead to a lower inclination to make charitable donations, because of:

(a) increasing health costs;

(b) decreasing attendance of religious services; 
(c) decreasing egocentric networks;

(d) specifying alternative ways of making charitable donations (e.g. charitable bequests);

(e) the presence (and perceived financial security) of alternative noncharitable beneficiaries.

\section{The cognitive ability hypothesis}

Recently, several studies originating in economics and sociology have found that cognitive abilities are an important factor driving prosocial behaviour (Bekkers 2005b; James 2011a, 2011b; Wiepking and Maas 2009). Sociologists have found that people who have stronger verbal proficiencies are known to be more generous charitable donors, and are more likely to agree to post-mortem organ donation (Bekkers 2005b). Wiepking and Maas (2009) show that higher verbal proficiency can largely account for the more generous charitable donations of the higher educated. Economists have come across the importance of various aspects of cognitive abilities for prosocial behaviour as well. James $(2011 b)$ shows that cognitive tests specifically involving spatial memory and drawing tasks were important factors in predicting charitable giving among a sample of cognitively normal seniors.

In order to understand how cognitive abilities influence charitable giving we can consider perspectives from psychology. Cognitive science shows that there are two routes that lead us to understand other people's emotions and facilitate prosocial behaviour: cognitive abilities - or more precisely cognitive perspective taking - and empathy (Decety and Jackson 2006; Hein and Singer 2008; Preston and De Waal 2002). Cognitive perspective taking relates to a situation where one 'represents the mental state of others, including affective states, without being emotionally involved' (De Vignemont and Singer 2006: 435). Cognitive perspective taking is also referred to as 'Theory of Mind' and functions through structures of the temporal lobe and para-limbic structures. In contrast, empathy concerns the embodied sharing of feelings of other people and relies on a different part of the brain: the sensorimotor cortices as well as limbic and para-limbic structures (Singer 2006). Because we focus in this article on cognitive abilities as an explanation of charitable behaviour, we will not further discuss the relationship between empathy and charitable giving (but for research on this relationship, see Batson and Powell 1998; Davis 1994; Sargeant and Woodliffe 2007).

According to the cognitive science literature, people with higher cognitive skills are better capable of taking other people's perspective (Hein and Singer 2008). They are more aware of, and better able to understand the 
needs of distant other people, which is the first of eight mechanisms explaining charitable behaviour deduced in a comprehensive literature review by Bekkers and Wiepking (2011). In order to make a charitable donation to organisations supporting people in need, potential donors need to be aware, have knowledge about and understand the needs of these distant others.

As mentioned, Bekkers $\left(205_{5} b\right)$, Wiepking and Maas (2009) and James $(2011 a, 2011 b)$ have shown a positive linear relation between cognitive abilities and charitable giving. If this finding is accurate, not only will increasing levels of cognitive abilities lead to increasing charitable giving, but decreasing levels of cognitive abilities should also lead to decreasing charitable giving. This could be an explanation for the lower probability of giving among those of oldest age. Those of oldest age typically experience a decline in cognitive abilities (John and Cole 1986; Phillips and Sternthal 1977). Decreasing levels of cognitive abilities among the oldest old lead to a decrease in perspective-taking abilities and hence result in lower probability of charitable giving.

An alternative explanation for a decrease in charitable giving caused by cognitive decline can be found in older people's reduced willingness and capacities to handle their financial affairs. Financial decision making requires a broad range of cognitive skills, and older people who experience cognitive decline might opt to have other people take over the responsibility for their finances (Moye and Marson 2007; Tilse et al. 2011 ). Or they might have their financial management taken over without their knowledge by family members, formal care-givers or government representatives, which can be problematic due to competing interests (Means and Langan 1996). Either way, when older people who have experienced cognitive decline are no longer responsible for their own finances, they are also no longer capable of making charitable donations. We expect that this alternative explanation will be more likely to explain the decreased inclination of charitable giving among those of older age that have experienced a strong cognitive decline, compared with moderate cognitive decline, as they are most likely to have lost financial control.

We summarise the arguments for the lower inclination to make charitable donations resulting from declining cognition in the cognitive ability hypothesis:

H2: Declining cognitive abilities lead to a lower inclination to make charitable donations, because of:

(a) decreasing perspective-taking abilities;

(b) the loss of control over financial management. 


\section{Data and measurements}

To test our hypotheses, we use five waves of the US Health and Retirement Study (HRS), collected between 1998 and 2006. The HRS is a national survey weighted to be representative of the entire US population over age $5^{\mathrm{O}}$; 1998 was the first year that the panel represented all individuals over the age

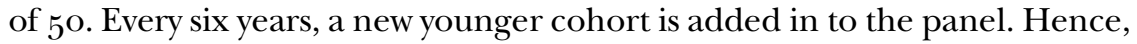
the HRS represents individuals over 5 o years of age in 1998 , individuals over $5^{2}$ years of age in 2000, individuals over 54 years of age in 2002, and then

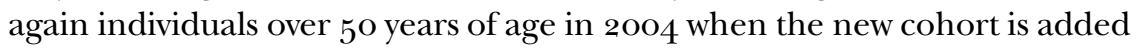
in, and individuals over $5^{2}$ years in 2006 .

In each wave, between 20,625 and 17,987 respondents participated, and the average respondent participated in 2.7 waves. We excluded the respondents who were unable to complete the survey themselves and needed assistance from a family member or health-care professional filling out the survey (representing between 2,026 and 1,240 respondents per wave). Among others, these proxy respondents could not complete the delayed word recall test, which we use as a measure of cognitive ability. In addition, some other questions we use in the analyses are very difficult to answer on behalf of someone else, such as questions on self-rated health. Analyses conducted with the full sample did not alter the results (results available from the authors). Furthermore, we excluded the 215 respondents over age $95(0.006 \%)$, because initial analyses showed inconsistent results for this small group. Excluding the respondents over 95 years of age also did not alter the results. Excluding the respondents who were unable to complete the survey themselves and those over 95 years of age resulted in a total of 85,607 observations included in the analyses.

\section{Measurements}

Our dependent variable is the presence of charitable giving. This measure is based upon whether, within the last 12 months, the respondent or respondent's spouse had donated 'money, property, or possessions totalling $\$ 5$ oo or more to religious or other charitable organisations (The United Way, the Heart Association, educational institutions, religious organisations or other such groups are charitable organisations)' (Institute for Social Research 2003: F5401). Forty-six per cent of the respondents indicated having made a donation over US $\$ 5$ oo. Philanthropic literature shows that, in many cases, charitable giving is decided upon by all adult members in the household. Partners in couple households are often both involved in making larger gifts (see e.g. Andreoni, Brown and Rischall 2003; Burgoyne, Young and Walker 2005; Wiepking 2007). In line with what is common in 
T A в L E 1 . Descriptive statistics

\begin{tabular}{lrrrr}
\hline & \multicolumn{1}{c}{ Mean } & \multicolumn{1}{c}{ SD } & Minimum & Maximum \\
\hline Charity & 0.463 & - & 0.0 & 1.0 \\
Age & 17.780 & 10.083 & 0.0 & 45.0 \\
Age squared & 41.801 & 410.339 & 0.0 & 2025.0 \\
Self-rated health (d) & 0.008 & 0.580 & -3.2 & 3.2 \\
Heart (d) & -0.001 & 0.183 & -0.8 & 0.8 \\
Cancer (d) & 0.000 & 0.134 & -0.8 & 0.8 \\
Stroke (d) & -0.002 & 0.116 & -0.8 & 0.8 \\
Cognitive ability (d) & -0.011 & 1.283 & -7.4 & 7.2 \\
Religious attendance (d) & -0.101 & 23.655 & -136.9 & 125.7 \\
Egocentric network (d) & 0.011 & 2.314 & -17.5 & 28.5 \\
Relative health costs (d) & -0.002 & 0.129 & -0.8 & 0.8 \\
Charitable bequest (d) & 0.000 & 0.123 & -0.8 & 0.8 \\
Self-rated health (m) & 3.156 & 0.970 & 0.6 & 5.0 \\
Heart (m) & 0.232 & - & 0.0 & 1.0 \\
Cancer (m) & $0.13 \mathrm{O}$ & - & 0.0 & 1.0 \\
Stroke (m) & 0.067 & - & 0.0 & 1.0 \\
Cognitive ability (m) & 4.418 & 1.671 & -0.4 & 1.0 \\
Religious attendance (m) & 36.302 & $26.94 \mathrm{O}$ & -84.9 & 144.8 \\
Egocentric network (m) & 2.012 & 2.085 & -7.1 & 35.0 \\
Relative health costs (m) & 0.079 & - & 0.0 & 1.0 \\
Charitable bequest (m) & 0.054 & - & 0.0 & 1.0 \\
& & & & \\
\hline
\end{tabular}

Notes: The negative values for persons' mean value on cognitive ability, religious attendance and egocentric network are an artefact of the multiple imputation procedure. The multiple imputation procedure is based on linear predictions, which can result in negative values. SD: standard deviation. m: person-specific mean (between-person component). d: deviation from the person-specific mean (within-person component).

Source: Pooled US Health and Retirement Survey data 1998-2006 (N=85,6o7; five waves; descriptive statistics obtained with first (of 20) imputed datasets).

philanthropic literature, the Health and Retirement Study measures donations by asking one respondent per household about the donations by the respondent and (if applicable) the respondent's spouse. All other variables included in our analyses relate to the respondent, and not to other household members. As a consequence, the coefficients of individual-level characteristics, such as self-rated health and cognitive ability, can be somewhat underestimated (Table 1 ).

Respondent's age and age squared were included in the analyses, where age $=5^{\circ}$ was included at value 0 , so that, for example, age $=95$ had a value of 45 . The average age of the respondents was 68 years. Self-reported health was the response to the question, 'Would you say your health is excellent, very good, good, fair, or poor?' 'Excellent' is coded as 5 , 'very good' as 4 , 'good' as 3, 'fair' as 2, and 'poor' as 1. The average score on self-reported health across all waves was 3.2 , which resembles 'fair' health. The cancer variable indicates the person's response to the question, 'Has a doctor ever told you that you have cancer or a malignant tumour, excluding minor skin 
cancer?' On average, 13 per cent of the respondents have ever been confronted with cancer. The stroke variable reflects the response to the question, 'Has a doctor ever told you that you had a stroke?', which was the case for 7 per cent of the respondents. Finally, the heart variable comes from the survey question, 'Has a doctor ever told you that you had a heart attack, coronary heart disease, angina, congestive heart failure, or other heart problems?' Not less than 23 per cent of the respondents have ever experienced these heart problems.

The delayed word recall task was used as a test of cognitive abilities. To obtain this variable, the interviewer read one of four possible lists of ten nouns to the respondent. After approximately five minutes of asking other survey questions, respondents were asked to name as many words from the original list as possible. Words could be recalled in any order and there was no penalty for naming incorrect words. The number of words correctly named, up to ten, was the respondent's score for the delayed word recall test. The average score of respondents on the delayed word recall test was 4.4 .

In order to account for the increasing relative health costs people encountered with decreasing health, we included the percentage of income the respondent spent on health costs. People spend on average 7.9 per cent of their income on health costs. Religious attendance was measured as times a year someone attends religious services using the question, 'About how often have you attended religious services during the past year?' (hereinafter simplified as attending 'church'). On average, respondents go to church ${ }_{3} 6$ times a year, about once every 1.5 week; 24 per cent of the respondents never attend church. Religious attendance was only measured among all respondents in the 2004 and 2006 waves.

People's egocentric network was measured with the following question: 'How often do you get together with any of your neighbours just to chat or for a social visit?' If people are in an assisted-living facility they were asked 'How often do you get together with people in or near the facility just for a chat or for a social visit?' These responses were then translated into a weekly scale. On average people reported 2.o social contacts with neighbours a week in 20o6. There were no questions to allow inclusion of all visits from nonneighbours. Thus, this measurement of egocentric network is limited to the network available from the immediate neighbourhood, rather than a person's entire egocentric network. A charitable bequest included in their will was indicated by 5.4 per cent of the respondents.

The HRS does not include a clear indicator for loss of control over own financial management. We therefore cannot test this hypothesis. Control variables include the natural $\log$ of income, the natural $\log$ of assets, homeownership, education, marital status, gender, and race/ethnicity. Income and assets reflect total imputed household amounts. Income 
includes all forms of income such as government transfers, wages, interest, and capital gains. Education reflects the number of years of formal education completed, up to 16 for a bachelor's graduate, or 17 for all graduate degrees. In order to account for the presence of alternative noncharitable beneficiaries, we included whether or not the respondent has children in the analyses; 93 per cent of the respondents indicated having at least one child.

The variables self-reported health, cognitive ability, egocentric network and education contained missing values (for $60,1448,4638$, and 167 cases, respectively). Also, religious attendance was only measured among all respondents in the 2004 and 2006 wave. We used a multiple imputation procedure (using the 'mi' module in Stata 11 ) to estimate and replace these missing values, enabling us to include all 85,607 observations in five waves in the analyses.

\section{Analytical strategy}

We performed longitudinal analyses using five waves of the HRS (1998-2006; $\mathrm{N}=85,607)$ using a hybrid approach as suggested by Allison (Allison 2009; Neuhaus and Kalbfleisch 1998). The hybrid approach allows us to combine time-constant and time-varying predictor variables, which is needed in order to evaluate the changes in the relationship between age, age squared and charitable giving over time, when including the explanatory variables to test the health and the cognitive ability hypothesis. In the hybrid approach each time-varying predictor variable is decomposed into a between-person component (included in the analyses as the person-specific mean, denoted with ' $m$ ') and a within-person component (included in the analyses as a deviation from the person-specific mean, with positive scores indicating a decline over time, denoted with ' $d$ '). A positive coefficient on the 'deviation from the person-specific mean variable' ' $\mathrm{d}$ ' indicates the effect of a higher score than the person-specific mean for that variable at that time-point. A significant odds ratio (OR) higher than 1 on the delayed word recall ' $d$ ' variable thus indicates that someone with a lower than (within-person) average score on the delayed word recall test on a specific time-point has a lower probability of making a donation. The results of the longitudinal change models are displayed in Table 2.

Next to the longitudinal change models, we test for mediation of the relation between age and giving using the KHB-method developed by Karlson, Holm and Breen (2010). The KHB-method decomposes the total effect of a variable into direct and indirect effects, and is specifically developed to overcome problems with mediation in analyses with binary dependent variables (for more details, see Karlson, Holm and Breen 2010; 
T A в L E 2. Longitudinal change models (hybrid model) explaining the presence of charitable giving over $\$ 5$ oo per year $(N=85,607)$

\begin{tabular}{|c|c|c|c|c|c|c|}
\hline & Model I & Model II & Model III & Model IV & Model V & Model VI \\
\hline & Age only & $\begin{array}{l}\text { Age and } \\
\text { controls }\end{array}$ & Health & Cognition & $\begin{array}{c}\text { Religious } \\
\text { attendance }\end{array}$ & $\begin{array}{c}\text { Complete } \\
\text { model }\end{array}$ \\
\hline & \multicolumn{6}{|c|}{ Odds ratios } \\
\hline Age & $1.059^{* * *}$ & $1.096^{* * * *}$ & $1.093^{* * *}$ & $1.095^{* * *}$ & $1.047^{* * *}$ & $1.05^{1 * * *}$ \\
\hline Age squared & $0.998 * * *$ & $0.999^{* * * *}$ & $0.999^{* * *}$ & $0.999^{* * *}$ & $1.000^{* *}$ & $1.000^{* *}$ \\
\hline Self-rated health (d) & & & $1.038^{*}$ & & & 0.975 \\
\hline Heart (d) & & & $0.776^{* * *}$ & & & o. $786^{* * *}$ \\
\hline Cancer (d) & & & 0.922 & & & 0.998 \\
\hline Stroke $(d)$ & & & o. $79^{*} *$ & & & 0.854 \\
\hline $\begin{array}{l}\text { Delayed word } \\
\text { recall }(\mathrm{d})\end{array}$ & & & & $1.040^{* * * *}$ & & $1.032 * * *$ \\
\hline $\begin{array}{l}\text { Religious } \\
\text { attendance }(\mathrm{d})\end{array}$ & & & & & $1.017^{* * *}$ & $1.017^{* * *}$ \\
\hline $\begin{array}{l}\text { Egocentric } \\
\text { network (d) }\end{array}$ & & & & & & $0.99^{8}$ \\
\hline $\begin{array}{l}\text { Relative health } \\
\text { costs (d) }\end{array}$ & & & & & & 1.089 \\
\hline $\begin{array}{l}\text { Charitable } \\
\text { bequest (d) }\end{array}$ & & & & & & 1.085 \\
\hline Self-rated health (m) & & & $1.465 * * *$ & & & $1.163^{* * * *}$ \\
\hline Heart $(\mathrm{m})$ & & & $1.423^{* * *}$ & & & $1.159 * *$ \\
\hline Cancer (m) & & & $1.3^{1} 6^{* * *}$ & & & $1.200^{* *}$ \\
\hline Stroke $(\mathrm{m})$ & & & $0.726 * *$ & & & 0.863 \\
\hline $\begin{array}{l}\text { Delayed word } \\
\text { recall }(\mathrm{m})\end{array}$ & & & & $1.161 * * *$ & & $1.106 * * *$ \\
\hline $\begin{array}{l}\text { Religious } \\
\text { attendance }(\mathrm{m})\end{array}$ & & & & & $1.053^{* * *}$ & $1.05^{1 * * *}$ \\
\hline $\begin{array}{l}\text { Egocentric } \\
\text { network }(\mathrm{m})\end{array}$ & & & & & & 0.996 \\
\hline $\begin{array}{l}\text { Relative health } \\
\text { costs }(\mathrm{m})\end{array}$ & & & & & & $3.916^{* * *}$ \\
\hline $\begin{array}{l}\text { Charitable } \\
\text { bequest }(\mathrm{m})\end{array}$ & & & & & & $5 \cdot 749^{* * * *}$ \\
\hline $\begin{array}{l}\text { Variance random } \\
\text { intercept } \\
\left(\operatorname{sigma}_{\mathrm{u}}\right)^{2}\end{array}$ & $2.4^{84}$ & 1.895 & 1.881 & 1.883 & 1.377 & 1.359 \\
\hline $\begin{array}{l}\text { Intraclass } \\
\text { correlation } \\
\text { (rho) }\end{array}$ & 0.784 & o.669 & o.666 & o.666 & 0.547 & $0.54^{2}$ \\
\hline
\end{tabular}

Notes: Respondents over 95 years of age $(\mathrm{N}=215$; $0.006 \%)$ were excluded from the analyses. Control variables included in models II to VI: income, assets, homeownership, marital status, children, education, gender, ethnicity. m: person-specific mean (between-person component). $\mathrm{d}$ : deviation from the person-specific mean (within-person component).

Source: Pooled US Health and Retirement Survey data 1998-20o6 (five waves; estimates based on 20 imputed datasets).

Significance levels: $* p \leqslant 0.05, * * p \leqslant 0.01, * * * p \leqslant 0.001$. 
Mood 2010). In nonlinear probability models the decomposition into direct and indirect effects is more complex than in linear regression models. In linear regression models, the coefficient of a key variable estimated in a model including the mediating variable is compared with a reduced model, which excludes the mediating variable. The difference in the coefficients of the key variable between the two models is the part of the total effect of the key variable that can be accounted for by the mediating variable: the indirect effect. In nonlinear probability models this decomposition is problematic, because the coefficients estimated in different models are not comparable with each other. Karlson, Holm and Breen (2010) developed the KHBmodule in Stata 11 to overcome this issue. The solution provided by the KHB-module is based on a rescaling of the models.

Finally, we estimate the predicted probability of making a donation, based on the estimations from the different longitudinal change models displayed in Table 2. These probabilities are displayed in Figure 1.

\section{Results}

Table 2 displays results of hybrid longitudinal change models explaining the presence of charitable giving in excess of $\$ 5$ oo per year. Model I of Table 2 displays the relationship between age and charitable giving, without controlling for any other variables, Model $\mathrm{I}$ in Table 2 demonstrates a curvilinear relationship between age and the presence of charitable giving. Age is significant and positive while age-squared is significant and negative. The ORs reported in Model II in Table 2 project to an age-giving relationship peaking at age 64 . In comparison: previous studies most commonly found charitable giving to increase with age until age 75 then decreasing afterwards (Andreoni 2001; Hodgkinson and Weitzman 1996; Midlarsky and Hannah 1989). Model II of Table 2 includes age as well as the control variables: income, assets, homeownership, education, marital status, gender, race/ethnicity, and having children (ORs for control variables not displayed, full results available from the author). The ORs reported in Model II in Table 2 project to an age-giving relationship peaking at age 85 . One possible explanation for this late-life decline in giving relates to changes in physical health, as we argued in our physical health hypothesis.

To consider this mechanism, Model III in Table 2 introduces the four health-related variables, self-rated health, previous diagnosis of cancer, previous diagnosis of stroke, and previous diagnosis of heart-related problems. As explained in the analytical strategy, the four health-related variables are included as a between-person component, the person-specific mean $(\mathrm{m})$, and a within-person component, the deviation from the 
(a)

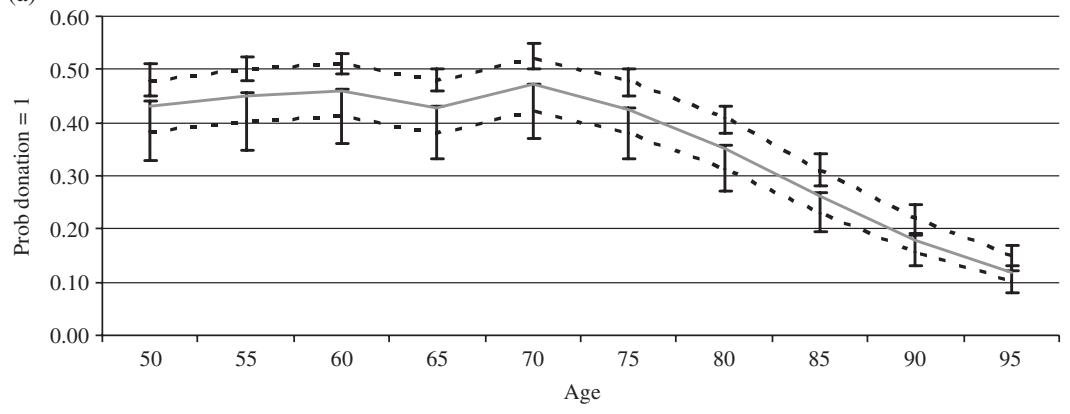

. - - - Model IIIa: poor health _ - - - Model IIIb: good health _ _ Average person

(b)

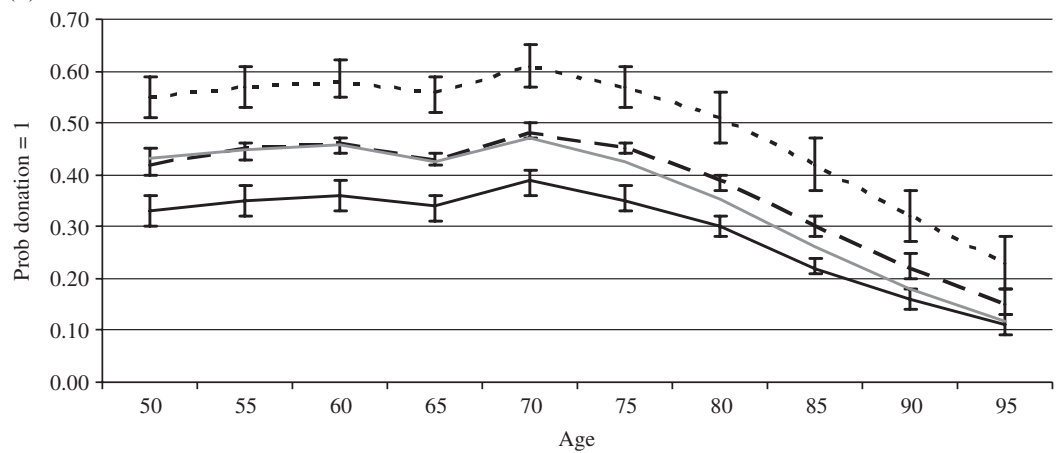

— Model IVa: bad cognition — - Model IVb: medium cognition - - - Model IVc: high cognition —— Average person

(c)

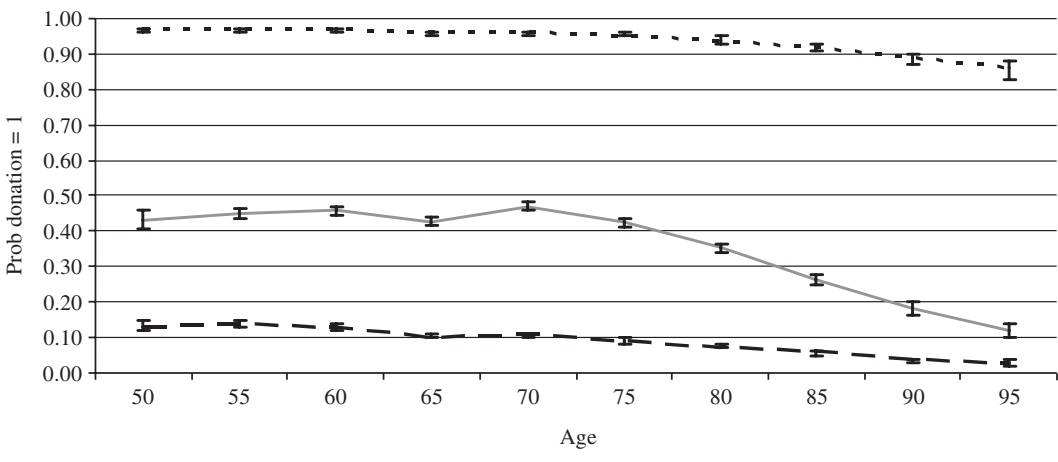

Figure 1. Predicted probabilities of making a charitable donation over $\$ 5$ oo by age: (a) for different health conditions; (b) for different levels of cognition; (c) for different levels of religious attendance (predicted probability of making a donation estimated at means of variables included in the analyses; results obtained with the first of 20 imputed datasets). 
person-specific mean (d). For self-rated health, the OR displayed for the person-specific mean $(\mathrm{m})$ indicates that someone with a one point higher score on self-rated health has a 47 per cent higher probability of making a charitable donation. Someone who has ever experienced a stroke has a 27 per cent lower probability of making a donation. Interestingly, having ever experienced heart problems or cancer increases the probability of making a donation by 42 and 32 per cent, respectively. A negative deviation score for a person for self-rated health (d) on a certain point in time indicates a lower than average self-rated health at that point in time for that person. The OR for the within-person deviation from the person-specific mean for self-rated health (self-rated health (d) in Model III of Table 2) corresponds with the possibility that decreasing health conditions may lead to a decrease in giving. When self-rated health is one point lower than a person's average self-rated health, the probability of giving is 4 per cent lower. A positive score on heart (d) and stroke (d) indicates that someone has experienced new heart problems or a stroke. The results in Model III of Table 2 thus show that experiencing new heart problems or a stroke leads to a decrease in the probability of making donations over $\$ 5$ oo per year.

While all of the health-related measurements are, in one form or another, significantly associated with charitable giving, the basic curvilinear relationship between age and giving remains significant after introducing these health variables. This can be seen in Table 3, displaying the total, direct, and indirect effects of age and age squared on the likelihood of making donations. Model III of Table 3 shows there is almost no change in the total, direct and indirect effects of age squared on the probability of making a donation compared with these effects in Model II in Table 3 (displaying the total, direct and indirect effects of age and age squared on giving for the model including only control variables). Hence, changes in health, as measured by the four health variables, explain only a very small part of the curvilinear age-giving relationship.

To further illustrate the limited mediating effect of health on the relationship between age, age squared and giving, we calculated the predicted probability of making a donation for people of different ages. Figure 1a shows the predicted probability of making a donation for someone in good health (upper line), someone in bad health (bottom line), compared with the predicted probability of making a donation for an average person (middle line; estimated at the mean of all variables). Essentially, the figure demonstrates the extent to which the curve is flattened by the introduction of the variable of interest. Such flattening, resulting from an increased relative probability of giving at older ages, suggests the extent to which the variable accounts for the downward trend in giving at older ages. Figure 1a shows a very modest upwards change in the probability of making 
T A B L 3 . Test of mediation age, age squared and charitable donations over $\$ 500$

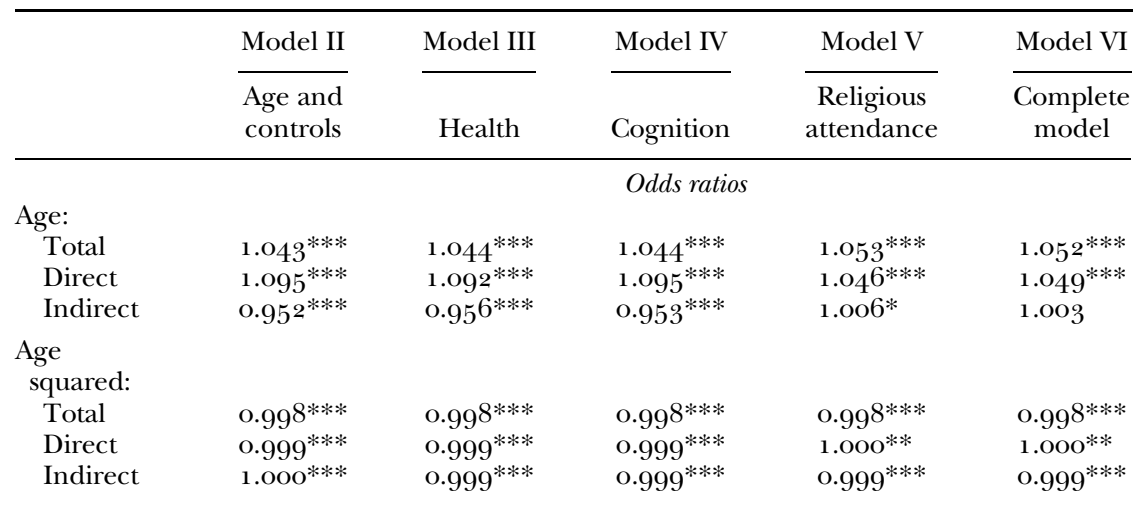

Source: Pooled US Health and Retirement Survey data 1998-2006 (five waves; estimates based on first of 20 imputed datasets).

Notes: Total, direct and indirect effects of age and age squared estimated on the likelihood of making a donation over $\$ 5$ oo, using the KHB-module in Stata 11 , developed by Karlson, Holm and Breen (2010). Models II-VI refer to the models as displayed in Table 2. Results obtained with the first of 20 imputed datasets, which can account for differences between Tables 2 and 3 . Significance levels: $* p \leqslant 0.05, * * p \leqslant 0.01, * * * p \leqslant 0.001$.

a donation by increasing age in the lines representing estimates from Model III (including the health variables). More pronounced is the difference in probability of making a donation for someone with either good or bad health. The average probability of making a donation for someone with very bad health is 0.36 , while this is 0.46 for someone with very good health. The predicted probability of making a donation by an average person is $0.4^{1}$.

Next, we discuss the test of the first part of the cognitive ability hypothesis: is the curvilinear relationship between age and giving mediated by cognitive abilities? Model IV of Table 2 shows that remembering on average one word more on the delayed word recall test increases the probability of donating by 16 per cent. We furthermore find that people who experience a decline in cognition over time have a lower probability of making donations. When people remember one word less than their average score on the delayed word recall test, this decreases their probability of making a donation by 4 per cent. Model IV in Table 3 displays the test for the mediating effect of cognitive abilities on the relationship between age, age squared and giving. As with the health variables, including the cognition variables only slightly changes the total, direct and indirect effects of age and age squared on the likelihood of making a donation. This is visually displayed in Figure $1 \mathrm{~b}$, 
which shows the predicted probabilities of making a donation at different ages for people with poor bad (bottom line), medium (upper middle line) and good (top line) cognitive abilities in comparison to the predicted probability of making donations for an average person (lower middle line). The average predicted probability of making a donation does differ strongly between people with bad, medium or strong average cognitive skills. They have a respective probability of making donations of $0.33,0.42$ and 0.55 .

In the health hypothesis, we argued that decreasing health conditions lead to a lower frequency of religious service attendance, which in turn would lead to a lower probability of giving. Because initial (cross-sectional) analyses of the data revealed a strong effect of religious attendance on the relationship between age and giving, we separately examined the effect of religious attendance in Model V of Table 2. Model V in Table 2 shows that people who attend ten more religious services a year have a 53 per cent higher probability of making a charitable donation. A negative deviation score for a person on religious attendance $(d)$ on a certain point in time indicates a lower than average religious attendance at that point in time for that person. This person has experienced a decline in religious attendance over time. A person who experiences a decline in religious attendance with ten times a year, experiences a decrease in the probability of giving of 17 per cent. Model V in Table 3 shows the results of the mediation test for religious attendance. The results indicate that, once religious attendance is included in the analyses, the OR for the direct effect of the age polynomial on the likelihood of making a charitable donation is estimated to be 1 .ooo. The curvilinear relationship between age and giving appears to be mediated by religious attendance. The oldest old less frequently attend church, and because of their lower religious attendance they are less likely to make charitable donations. In Models II, III and IV we also found an indirect effect of age in years on giving. Model V shows that this indirect effect of age can be largely accounted for by religious attendance. This is becomes more clear in Figure 1c, which shows the predicted probability of making donations, for people with very high (top line) and very low (bottom line) religious attendance, plotted against the predicted probability of making a donation by an average person (middle line). Figure 1c shows the strongest upwards change in the probability of making a donation by increasing age for the lines representing the predicted probability of making a donation at high or low religious attendance, compared to the predicted probability of making a donation for an average person. There is almost no downward curvature left, in line with the results from Model V in Tables 2 and 3. From Figure 1c we also learn that the predicted probability of making a donation for someone with very high religious attendance (more than two times a week) is on average 0.96 , almost 1.0 . At age $5^{\mathrm{o}}$, the probability starts at 0.97 , which 
gradually declines to 0.86 at age 95 . For someone never attending church, this probability is on average 0.10 , starting at 0.13 at age 50 , declining to 0.03 at age 95 .

Model VI in Table 2 displays the results for the complete model. This model includes the other hypothesised factors explaining the relationship between health, age and giving, in addition to religious attendance which we separately examined in Model V. We will refer to the first set of these factors as the 'health-mediators': egocentric network, relative health costs and charitable bequests. In contrast to our expectations, we do not find a relationship between the average number of neighbours visiting and charitable giving. Unexpectedly we find that the average percentage of income spent on health costs relates positively to the presence of charitable giving. Apparently people do not experience higher relative health-care costs as a limitation to giving more than $\$_{5}$ oo. We do not find an effect of changes in the average percentage spent on health costs on giving. Having a charitable bequests in one's will does strongly increase the likelihood of inter vivos giving, as we find that having a planned charitable bequest increases the probability of life-time donations by more than 570 per cent. Changes over time in both egocentric network and leaving a charitable bequest have no effect on the likelihood of making donations.

The results for the mediation test of the relationship between age, age squared and giving in Model VI in Table 3 are very similar to the results for mediation from Model $\mathrm{V}$ in Table 3. The only difference is that the indirect effect of age is no longer significant. This indicates that the indirect effect of age on giving over $\$ 5$ oo can be accounted for by all variables included in Model VI, but especially by religious attendance, which we identified as a health mediator.

\section{Conclusion and discussion}

Previous studies have shown that in Western societies, charitable giving increases with age, until the ages between $6_{5}$ and 75 , after which it declines with further age (e.g. Andreoni 2001; Halfpenny 1991; Wu, Huang and Kao 2004). The first aim of the present study was to explain why the oldest old are less inclined to make charitable donations. We argued that the lower inclination to donate among the oldest old could be explained either by the health hypothesis or the cognitive ability hypothesis.

In the health hypothesis we stated that declining health conditions among the oldest old lead to a lower inclination to make charitable donations, because of increasing health costs, decreasing attendance of religious 
services, decreasing egocentric networks, specifying alternative ways of making charitable donations (e.g. charitable bequests) and the presence (and perceived financial security) of alternative non-charitable beneficiaries. With the cognitive ability hypothesis we argued that declining cognitive abilities among the oldest old lead to a lower inclination to make charitable donations, because of decreasing perspective-taking abilities and the loss of control over financial management.

The longitudinal analyses showed that the curvilinear relationship between age and giving is mediated most notably by religious attendance. During people's last life stages they on average decrease their level of church attendance. People are often asked to make both religious and secular charitable donations in church. Attending church at lower rates at the oldest ages leads these people to receive fewer requests for donations, and this consequently leads them to have a lower inclination to donate more than $\$ 5$ oo. Additional analyses showed that people with declining self-rated health increased their religious attendance, rather than decreased it as hypothesised. As we showed that the relationship between age and giving was partly mediated by religious attendance and only to a limited extent through health-related characteristics (as hypothesised), this finding does not alter our conclusions.

The decline in charitable donations at the oldest ages was to a small extent mediated by a decline in cognitive abilities, as predicted by the cognitive ability hypothesis. Cognitive skills enable people to take other people's perspective, and understand the needs of distant other people, which facilitates charitable giving (Bekkers and Wiepking 2011; Hein and Singer 2008). We found modest evidence that declining cognitive abilities at older age led to a lower inclination to make charitable donations over $\$ 5$ oo.

Despite the interesting findings, there are also some limitations to this study. First, the Health and Retirement Study includes only measures for religious attendance in the 2004 and 2006 waves. We used multiple imputation procedures in order to analyse changes in religious participation across all five waves included in our analyses. We used several different estimation procedures, and analysed the 2004 and 2006 waves separately to test the robustness of the findings in this paper. Results from these different estimation procedures are comparable to the results reported in this paper (results available from the authors). Secondly, in our analyses we study the changes in the probability of making a donation over $\$ 5$ oo. Although our results facilitate a better understanding of the changes in the probability of making a substantial donation at older age, they cannot facilitate a better understanding of changes in the amount people give at older ages. The amount people give at older ages can change significantly without changing 
the probability of giving over $\$ 5$ oo. A decline in a yearly donation from $\$ 15$ oo to $\$ 55$ o will not be reflected by a change in our dependent variable, which only expresses changes in incidence of giving over $\$ 500$. Our results need to be interpreted with this in mind. Thirdly, we were unable to include a measurement for loss of financial control. This measure was unavailable in the Health and Retirement Study. It could be that loss of financial control mediates the relationship between age and giving.

Future research could expand upon the current research by examining changes in the amount people give, but could also focus on the decline of other types of prosocial behaviour at older ages, including volunteering. Although Einolf (2009) predicts that in the USA the generation of babyboomers (born 1946-1955) will be more active volunteers in the near future than the generations of the silent cohort (born 1936-1945) and the long civic cohort (born 1926-1935) were at the same ages, there is evidence for a decline in volunteering among the older old. In a study of 207 older volunteers, Tang, Morrow-Howell and Choi (2010) examine explanations for attrition in older volunteers. The main reasons for those of older age to stop volunteering are a higher priority of another productive activity or commitment, problems with the programme administration, and declining health. If the mechanisms behind volunteering in older age are to some extent similar to the mechanisms behind charitable giving, one might expect that an additional explanation for the decline in volunteering at older ages could be the decline in religious participation.

The second aim of the present study was to facilitate better understanding of the generosity of those of older age. As argued in the introduction, this paper focused on the societal outcomes of charitable giving, rather than on the individual outcomes, as is more common in the gerontology literature. Those of older age are substantial contributors to the non-profit sector, and understanding how and why people experience a decline in giving at the oldest age can be beneficial to society at large.

This paper discusses why older adults decrease their donations to nonprofit organisations, using data from the USA to test our hypotheses. The implications of our results are, however, not limited to the USA. Although there are many differences between the non-profit landscapes of Western countries, they appear to be similar in their neglect of the older donor. As we discussed in the introduction, across Western countries older people experience a decline in philanthropic giving (Halfpenny 1991; Landry et al. 2006; Wiepking 2010; Wu, Huang and Kao 2004). Both in the USA and Europe, demographic shifts are taking place such that the proportion of people over the age of $6_{5}$ continues to increase rapidly. In 2005 in the USA, about 12 per cent of the population consisted of people over $6_{5}$, while this was 16 percent for Europe (Eurostat 2010). The US Census Bureau expects 
the proportion of the population over the age of $6_{5}$ in the USA to double between 2000 and 2030 (He et al. 2005: 183). Eurostat indicates that persistently low fertility rates, increasing life expectancy, and a baby-boom generation that will soon start to reach retirement age will lead to increasing older populations in Europe, with expectations of 24 per cent of the population being over $6_{5}$ in 2030 , and $3^{\circ}$ per cent being over $6_{5}$ in 2060 (Eurostat 2010: 168).

Our paper shows that the drop in charitable gifts by those of oldest age can be largely accounted for by the decreasing opportunities for giving that the oldest old experience. Attending religious services less frequently at older age decreases the number of requests for charitable gifts these people receive, resulting in lower charitable-giving behaviour.

Across Western societies, fundraising professionals should organise other charitable-giving opportunities for those of oldest age, to compensate for the decline in giving due to decreased religious attendance. Fundraising events are rarely targeted at older people. The March of Dimes' March for Babies, the London Bikeathon for Leukaemia and Lymphoma Research, and the Dutch Cancer Association's climb of Alpe d'HuZes (in which sponsored cyclists climb the Alpe d'Huez six - 'zes' in Dutch - times) clearly do not have the older old as target population in mind. But even less physical fundraising events often overlook those of oldest age as potential donors. Fundraisers should consider the potential contribution those of older age are capable of and willing to make. Simple changes could have a significant impact, such as making events more accessible, arranging transportation, and intentionally creating opportunities for involvement directed at older donors and volunteers.

\section{Acknowledgements}

The authors would like to thank Niels Schenk and Maarten Buis who significantly contributed to this paper by lending advice on the statistical procedures. Any errors are solely the responsibility of the authors. Pamala Wiepking was supported by grant 45-o9-022 from the Netherlands Organization for Scientific Research (NWO). NWO was not involved in conducting this study. The HRS (Health and Retirement Study) is sponsored by the National Institute on Aging (grant number NIA Uo1AGoo9740) and is conducted by the University of Michigan.

\section{References}

Allison, P. D. 2009. Fixed Effects Regression Models. Sage, Los Angeles.

Andreoni, J. 2001. The economics of philanthropy. In Smelser, N. J. and Baltes, P. B. (eds), International Encyclopedia of the Social and Behavioral Science. Elsevier, London, $11369-76$. 
Andreoni, J., Brown, E. and Rischall, I. 2003. Charitable giving by married couples. Who decides and why does it matter? The Journal of Human Resources, 38, 1,111 - 133 .

Baltes, P. B. and Baltes, M. M. 1990. Psychological perspectives on successful ageing: the model of selective optimization and compensation. In Baltes, P. B. B. and Baltes, M. M. (eds), Successful Ageing: Perspectives from Behavioural Sciences. Cambridge University Press, New York, 1-34.

Barlow, J. and Hainsworth, J. 2001. Volunteerism among older people with arthritis. Ageing Eं Society, 2 1, 2, 203-17.

Batson, C. D. and Powell, A. A. 1998. Altruism and prosocial behavior. In Gilbert, D. T., Fiske, S. T. and Lindzey, G. (eds), The Handbook of Social Psychology. Oxford University Press, New York, 282-316.

Bekkers, R. 2005a. It's not all in the ask. Effects and effectiveness of recruitment strategies used by nonprofits in the Netherlands. Paper presented at the 34rd Annual ARNOVA Conference, Washington DC, November 1 7-19, 2005.

Bekkers, R. 2005 $b$. Traditional and health related philanthropy: the role of resources and personality. Social Psychology Quarterly, 69, 4, 349-66.

Bekkers, R. and Wiepking, P. 2007. Generosity and philanthropy: a literature review. SSRN Working Paper Series No. $10155^{\circ} 7$, Science of Generosity Resource Paper.

Bekkers, R. and Wiepking, P. 2011. A literature review of empirical studies of philanthropy: eight mechanisms that drive charitable giving. Nonprofit and Voluntary Sector Quarterly, 4o, 5, 924-73.

Broese Van Groenou, M. and Deeg, D. 2010. Formal and informal social participation of the 'young-old' in the Netherlands in 1992 and 2002. Ageing $\mathcal{E}^{\circ}$ Society, 3o, 3, $445^{-6} 5$.

Bryant, W. K., Slaughter, H. J., Kang, H. and Tax, A. 2003. Participating in philanthropic activities: donating money and time. Journal of Consumer Policy, 26, 1, 43-73.

Burgoyne, C. B., Young, B. and Walker, C. M. 2005. Deciding to give to charity: a focus group study in the context of the household economy. Journal of Community E Applied Social Psychology, 15, 5, 383-405.

Choi, N.G. and Kim, J. 2010. The effect of time volunteering and charitable donations in later life on psychological wellbeing. Ageing $\mathcal{E}^{2}$ Society, 31 , 4, 590-610.

Cornwell, B., Laumann, E. O. and Schumm, L. P. 2008. The social connectedness of older adults: a national profile. American Sociological Review, 73, 2, $185^{-203}$.

Daneshvary, N. and Luksetich, W. A. 1997. Income sources and declared charitable tax deductions. Applied Economics Letters, 4, 5, 271-4.

Danko, W. D. and Stanley, T.J. 1986. Identifying and reaching the donation prone individual: a nationwide assessment. Journal of Professional Services Marketing 2, Fall/ Winter, $117-22$.

Davis, M. H. 1994. Empathy: A Social Psychological Approach. Brown \& Benchmark Publishers, Madison, Wisconsin.

De Vignemont, F. and Singer, T. 20o6. The empathic brain: how, when and why? Trends in Cognitive Sciences, 10, 10, $435^{-41}$.

Decety, J. and Jackson, P. L. 2006. A social-neuroscience perspective on empathy. Current Directions in Psychological Science, 15, 2, 54-8.

Edmundson, B. 1986. Who gives to charity? American Demographics, November, $45^{-9}$.

Edwards, K. P. 1991. Planning for family asset transfers. Financial Counselling and Planning, 2, 1, $55^{-78 .}$

Einolf, C.J. 2009. Will the boomers volunteer during retirement? Comparing the baby boom, silent and long civic cohorts. Nonprofit and Voluntary Sector Quarterly, $\mathbf{3}^{8}$, 2, $191-9$.

Eurostat 2010. Europe in Figures. Eurostat Yearbook. Publications Office of the European Union, Luxembourg. 
Giving USA 2009. Giving USA 2009: The Annual Report on Philanthropy for the Year 2008. Giving USA Foundation in conjunction with the Centre on Philanthropy, Indiana University, Indianapolis, Indiana.

Halfpenny, P. 1991. The 1989/9o charity household survey. In McQuillan, J. (ed.), Charity Trends. Charities Aid Foundation, Tonbridge, UK.

Hatch, L. R. and Bulcroft, K. 1992. Contact with friends in later life: disentangling the effects of gender and marital status. Journal of Marriage and the Family, 54, 1, 222-32.

Havens, J.J. and Schervish, P. G. 2003. Why the \$4I Trillion Wealth Transfer Estimate is Still Valid: A Review of Challenges and Questions. Social Welfare Research Institute, Boston College, Boston, Massachusetts.

He, W., Sengupta, M., Velkoff, V.A. and DeBarros, K. A. $2005.65+$ in the United States: 2005. In Current Population Reports: Special Studies. US Census Bureau, Washington DC.

Hein, G. and Singer, T. 2008. I feel how you feel but not always: the empathic brain and its modulation. Current Opinion in Neurobiology, 18, 2, $153-8$.

Hodgkinson, V. and Weitzman, M. S. 1996. Giving and Volunteering in the United States: Findings from a National Survey. Independent Sector, Washington DC.

Hurd, M. 2009. Inter-vivos giving by older people in the United States: who received financial gifts from the childless? Ageing $\mathcal{E}$ Society, 29, 8, 1207-25.

Institute for Social Research 2003. Codebook: HRS I998 Core Final Release. Available online at http://hrsonline.isr.umich.edu/modules/meta/1998/core/codebook/ h98j_h.htm\#JF5401H [accessed 27 February 2012].

Internal Revenue Service 2007. Statistics of Income-20o6 Individual Income Tax Returns. Internal Revenue Service, Washington DC.

James III, R. N. 2009. Health, wealth, and charitable estate planning: a longitudinal examination of testamentary charitable giving plans. Nonprofit and Voluntary Sector Quarterly, 38, 6, 1026-43.

James III, R. N. 2011 a. Charitable giving and cognitive ability. International Journal of Nonprofit and Voluntary Sector Marketing, 16, 1, 70-83.

James III, R. N. 2011 b. Cognitive skills in the charitable giving decisions of the elderly. Educational Gerontology, 37, 7, 559-73.

John, D. R. and Cole, C.A. 1986. Age differences in information processing: understanding deficits in young and elderly consumers. The Journal of Consumer Research, 13, 3, 297-315.

Karlson, K. B., Holm, A. and Breen, R. 2010. Comparing Regression Coefficients Between Models Using Logit and Probit: A New Method. Available online at http://ssrn.com/ abstract=1436349 [Accessed 7 April 2011 ] .

Knulst, W. and Eijck, K. V. 20o6. Old soldiers never die: explaining the disproportionate aging of volunteers in the Netherlands between 1985 and 20oo. Acta Sociologica, 49, 2, $185^{-200 .}$

Landry, C. E., Lange, A., List, J. A., Price, M. K. and Rupp, N. G. 20o6. Toward an understanding of the economics of charity: evidence from a field experiment. Quarterly Journal of Economics, $121,2,747-82$.

Lemon, B. W., Bengtson, V. L. and Peterson, J. A. 1972. An exploration of the activity theory of aging: activity types and life satisfaction among in-movers to a retirement community. Journal of Gerontology, 27, 4, $5^{1} 1-23$.

Longino, C. F. and Karl, C. S. 1982. Explicating activity theory: a formal replication. Journal of Gerontology, 37, 6, 713-22.

Ma, Q. 2002. Defining Chinese nongovernmental organizations. Voluntas: International Journal of Voluntary and Nonprofit Organizations, 13, 2, $113-30$.

Marsden, P. V. 1987. Core discussion networks of Americans. American Sociological Review, 52, 1, 122-31. 
Maxfield, M., Kluck, B., Greenberg, J., Pyszczynski, T., Cox, C. R., Solomon, S. and Weise, D. 2007. Age-related differences in responses to thoughts of one's own death: mortality salience and judgments of moral transgressions. Psychology and Ageing, 22, 2, 341-53.

Means, R. and Langan, J. 1996. Money 'handling', financial abuse and elderly people with dementia: implications for welfare professionals. Health and Social Care in the Community, 4, 6, 353-58.

Midlarsky, E. and Hannah, M. E. 1989. The generous elderly: naturalistic studies of donations across the life span. Psychology and Ageing, 4, 3, 346-51.

Mood, C. 2010. Logistic regression: why we cannot do what we think we can do, and what we can do about it. European Sociological Review, 26, 1, 67-82.

Moye, J. and Marson, D. C. 2007. Assessment of decision-making capacity in older adults: an emerging area of practice and research. Journals of Gerontology: Psychological Sciences and Social Sciences, 62B, 1, 3-1 1.

Munnell, A. and Sundén, A. E. 2003. Death and Dollars: The Role of Gifts and Bequests in America. Brookings Institution Press, Washington DC.

Neuhaus, J. M. and Kalbfleisch, J. D. 1998. Between- and within-cluster covariate effects in the analyses of clustered data. Biometrics, 54, 2, 638-45.

NHIS 2006-08. Chronic Conditions. National Center for Health Statistics. Health Data Interactive. Available online at http://205.207.175.93/HDI/TableViewer/ tableView.aspx?ReportId=101.

Nieswiadomy, M. and Rubin, R. M. 1995. Change in expenditure patterns of retirees: 1972-1973 and 1986-1987. Journals of Gerontology: Psychological Sciences and Social Sciences, 5oB, 5, S274-9o.

Penner, L.A., Dovidio, J.F., Piliavin, J.A. and Schroeder, D. A. 2005. Prosocial behavior: multilevel perspectives. Annual Review of Psychology, 56, $3^{6} 5^{-92}$.

Phillips, L. W. and Sternthal, B. 1977. Age differences in information processing: a perspective on the aged consumer. Journal of Marketing Research, 14, 4, 444-57.

Preston, S. D. and De Waal, F. B. M. 2002. Empathy: its ultimate and proximate bases. Behavioral and Brain Sciences, 25, 1, 1-72.

Sargeant, A. and Shang, Y. 2008. Identification, Death and Bequest Giving. A Report to AFP and Legacy Leaders. Indiana University, Indianapolis, Indiana.

Sargeant, A. and Woodliffe, L. 2007. Individual giving behaviour: a multi-disciplinary review. In Sargeant, A. and Wymer, W. (eds), The Nonprofit Marketing Companion. Routledge, London, $111-44$.

Schervish, P. G., Havens, J.J. and O’Herlihy, M. 2006. Charitable giving: how much, by whom, to what and why. In Powell, W. W. and Steinberg, R. (eds), The Nonprofit Sector: A Research Handbook. Yale University Press, Boston, Massachusetts, 542-67.

Schnittker, J. 2007. Look (closely) at all the lonely people: age and the social psychology of social support. Journal of Aging and Health, 19, 4, 659-82.

Shaw, B.A., Krause, N., Liang, J. and Bennett, J. 2007. Tracking changes in social relations throughout late life. Journals of Gerontology: Social Sciences, 62B, 2, S9o-9.

Singer, T. 2006. The neuronal basis and ontogeny of empathy and mind reading: review of literature and implications for future research. Neuroscience $\mathcal{E}^{\circ}$ Biobehavioral Reviews, 3o, 6, $855^{-63}$.

Tang, F., Morrow-Howell, N. and Choi, E. 2010. Why do older adult volunteers stop volunteering? Ageing $\mathcal{E}$ Society, 30, 5, 859-78.

Tilse, C., Wilson, J., Rosenman, L., Morrison, D. and McCawley, A.-L. 201 1 . Managing older people's money: assisted and substitute decision making in residential agedcare. Ageing E Society, 31, 1, 93-109. 


\section{$5^{10}$ Pamala Wiepking and Russell N. James III}

Van Tilburg, T. and Broese van Groenou, M. 2002. Network and health changes among older Dutch adults. Journal of Social Issues, 58, 4, 697-713.

Wheeler, J.A., Gorey, K. M. and Greenblatt, B. 1998. The beneficial effects of volunteering for older volunteers and the people they serve: a meta-analysis. The International Journal of Aging \& Human Development, 47, 1, 69-79.

Wiepking, P. 2007. The philanthropic poor: in search of explanations for the relative generosity of lower income households. Voluntas, 18, 4, 339-58.

Wiepking, P. 2010. Giving to particular charitable organizations: do materialists support local organizations and do democrats donate to animal protection? Social Science Research, 39, 6, 1073-87.

Wiepking, P. and Breeze, B. 2012. Feeling poor, acting stingy: the effect of money perceptions on charitable giving. International Journal of Nonprofit and Voluntary Sector Marketing, 17, 1, 13-24.

Wiepking, P. and Maas, I. 20og. Resources that make you generous: effects of social and human resources on charitable giving. Social Forces, 86, 4, 1973-96.

Wu, S.-Y., Huang, J.-T. and Kao, A.-P. 2004. An analysis of the peer effects in charitable giving: the case of Taiwan. Journal of Family and Economic Issues, 25, 4, $483-505$.

Accepted 20 January 2OI 2; first published online 23 March 2012

Address for correspondence: Pamala Wiepking, Department of Sociology \&

Erasmus Centre for Strategic Philanthropy (ECSP),

Faculty of Social Sciences, Erasmus University Rotterdam,

M-building (M6-44), P.O. Box 1738 ,

3ooo DR Rotterdam, The Netherlands.

E-mail: wiepking@fsw.eur.nl 